\title{
Intradural extramedullary cystic schwannoma of the cervical spine
}

\author{
Elif Başaran Gündoğdu๑, Mehmet Ali Ekici $\odot$
}

Department of Neurosurgery, University of Health Sciences, Bursa Yüksek İhtisas Training and Research Hospital, Bursa, Turkey

DOI: $10.18621 /$ eurj.384041

\begin{abstract}
Giant cervical intradural extramedullary schwannoma with severe spinal cord compression is a rare entity. Tumor spread and size are very important for surgical approach. In this case, we report a 55-years-old male patient with a giant intradural-extramedullary cervical schwannoma extending between C5 and T1 and causing spinal cord compression that underwent total resection with laminoplasty at C5-6-7 levels. The patient developed no additional deficit. To preserve the cervical lordosis, the patient used a cervical collar for three months. There has been no recurrence during two years of follow-up. Using the appropriate surgical method is essential in patients with spinal tumor in order to avoid additional neurological deficits and achieve cure.
\end{abstract}

Keywords: cervical schwannoma, laminoplasty, intradural extramedullary tumor

Received: January 25, 2018; Accepted: July 5, 2018; Published Online: August 15, 2018

$S^{\mathrm{n}}$ pinal schwannomas are slow-growing tumors of benign origin, which represent approximately $30 \%$ of all primary spinal cord tumors. Spinal schwannomas are most commonly intradural [1]. Extradural involvement becomes more pronounced for the cervical schwannomas, since the intradural segment of the nerve root is shorter at the cervical region compared to the other areas of the spinal cord. The general approach is laminectomy for cervical schwannomas, or unilateral facetectomy may be performed if the lesion is located laterally [2].

Giant intradural extramedullary schwannoma of the cervical spine has a low incidence and causes severe spinal cord compression. These patients present progressive motor and/or sensory deterioration [3].

\section{CASE PRESENTATION}

A 55-year-old male patient who had numbness and pain in his right arm and numbness in his right leg was admitted to the outpatient clinic. The neurological examination revealed hyperactive upper and lower extremity deep tendon reflexes (DTRs) and a positive Rhomberg test. Bilateral hypoesthesia was present at the C5-6-7-T1 dermatomes, although it was more pronounced on the right side. There was 1-2/5 weakness of the right arm. A cervical MRI study was performed. On the cervical MRI, there was an intradural extramedullary solid mass including cystic areas, which was extending between $\mathrm{C} 5$ and $\mathrm{T} 1$, compressing the spinal cord from the left side, and

Address for correspondence: Elif Başaran Gündoğdu, MD., University of Health Sciences, Bursa Yüksek İhtisas Training and Research Hospital, Department of Neurosurgery, Emniyet Caddesi No:35, 16115 Yıldırım, Bursa, Turkey

E-mail:basaran.elif@hotmail.com,Phone:+902242955000,Fax:+902243660416 


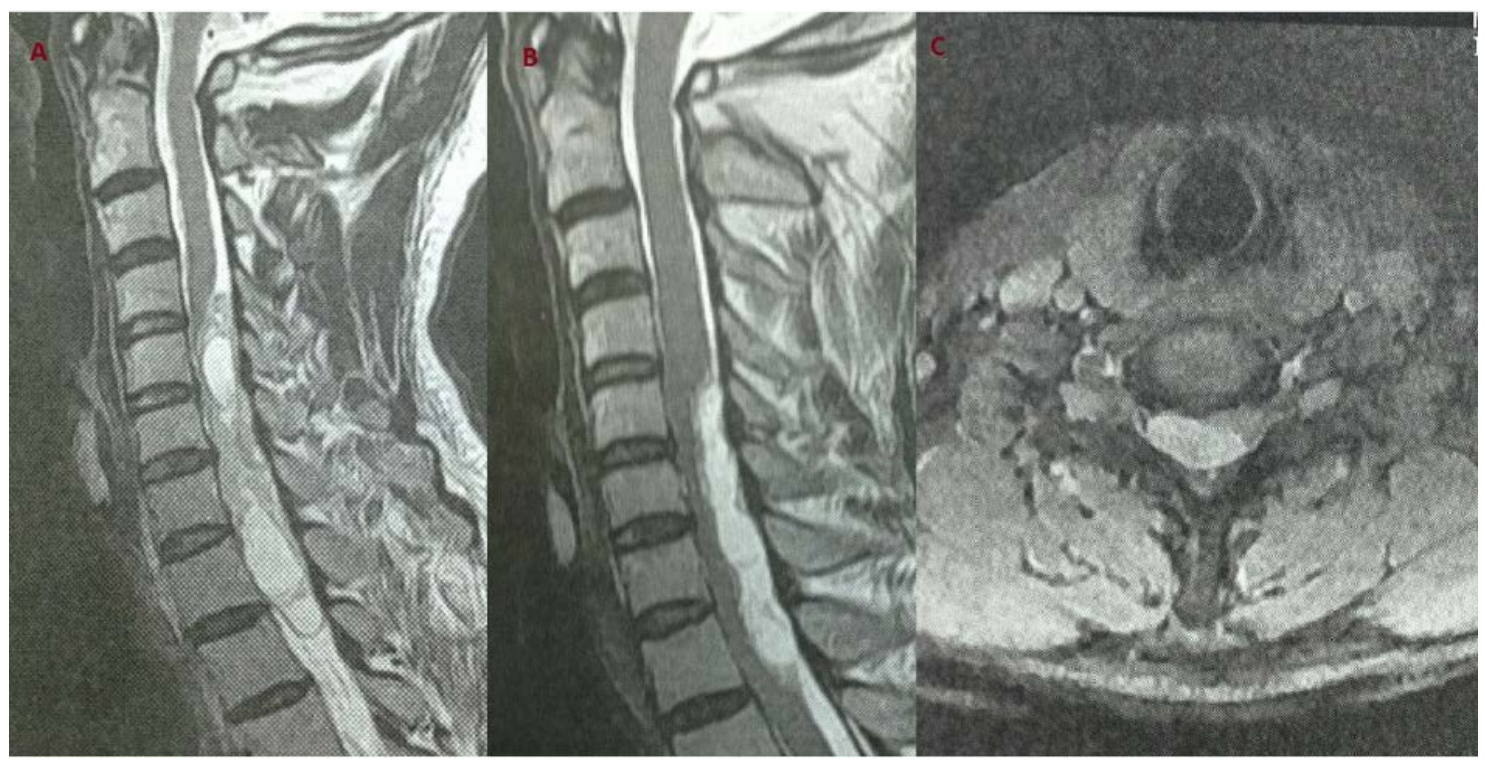

Figure 1. (A-B-C) Cervical MRI taken preoperatively.

enhancing homogeneously with gadolinium (Figure $1 \mathrm{~A}, 1 \mathrm{~B}$ and $1 \mathrm{C})$. In the opeeration, after laminectomy at C5-6-7 levels (Figure 2A and 2B), a midline incision was made on the dura and gross total resection of the tumor mass was completed. On macroscopic examination, the specimen was a solid-to-cystic mass which was grayish-white in color and was partly adherent to the arachnoid (Figure 2C). Then the dura was sutured and laminoplasty was performed after hemostasis of the surgical area with cautious electrocautery (Figure 2D). On histopathological examination, hypo- and hypercellular areas (Figure

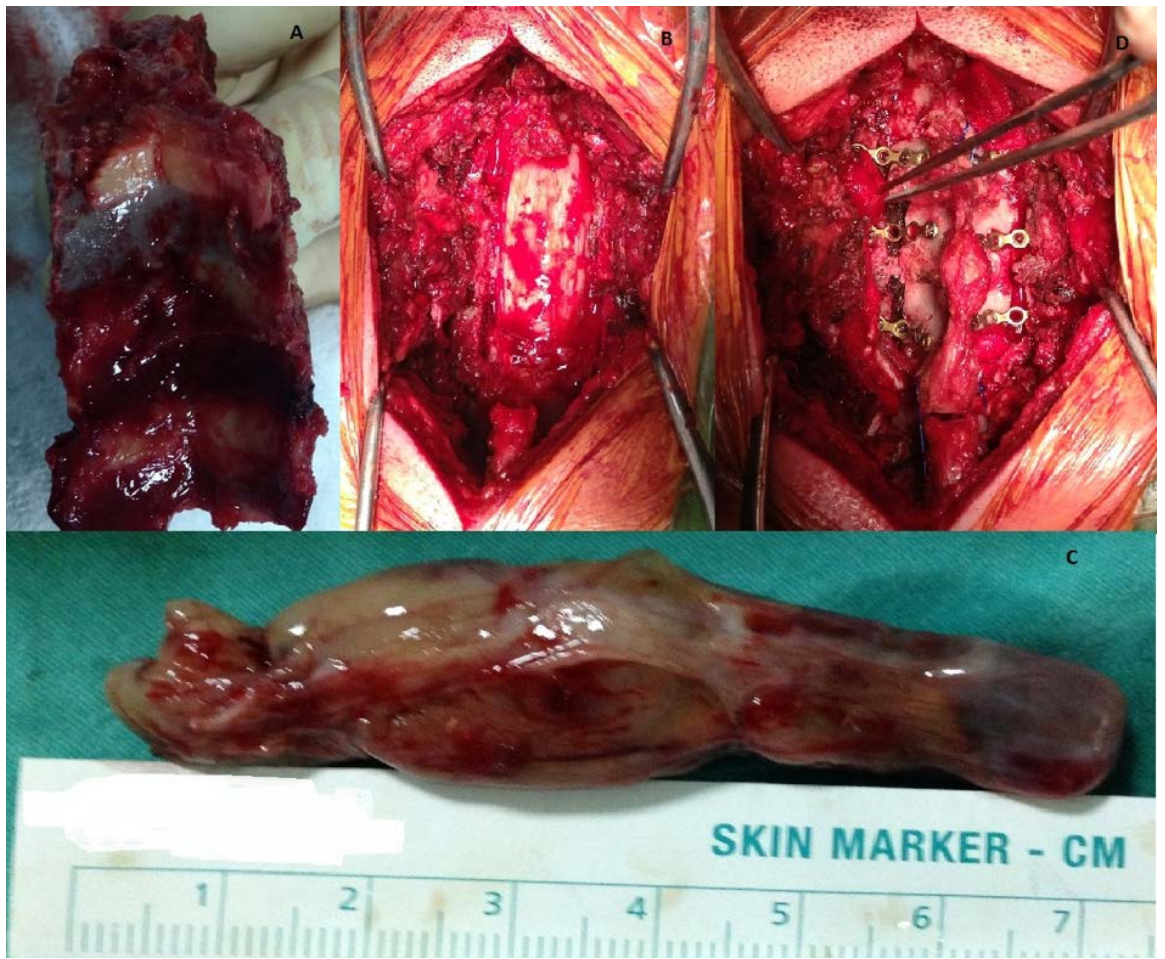

Figure 2. (A-B-C-D) During the operation laminoplasty and tumor mass. 


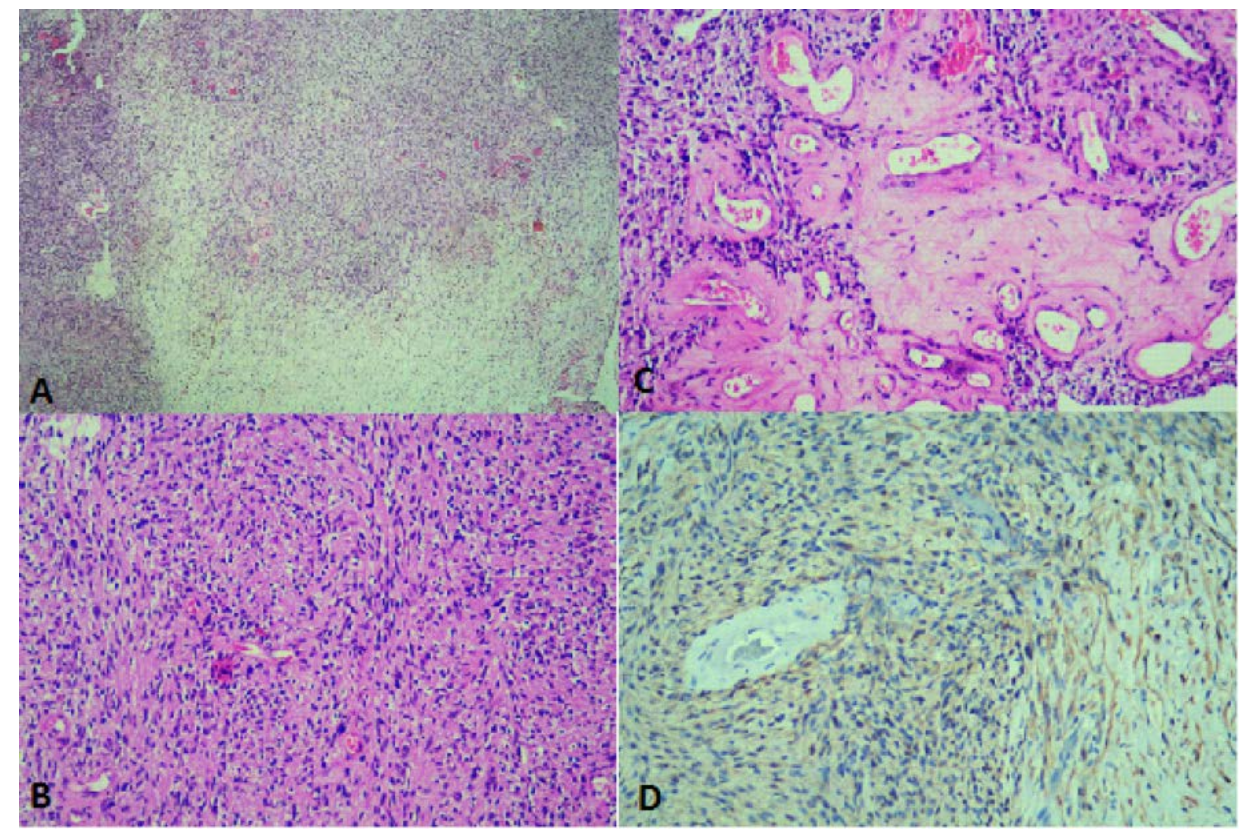

Figure 3. (A-B-C-D) Histopathological examination.

3A), Atoni A areas (Figure 3B), perivascular hyalinization (Figure 3C), and positive immunohistochemical staining for S-100 protein confirmed the diagnosis of schwannoma. During the first three months postoperatively, the patient used a cervical collar for preservation of the natural cervical lordosis. At the end of the postoperative third month, there was no severe kyphosis on the cervical X-ray
(Figure 4A and 4B). The patient was followed up for two years with no recurrence.

\section{DISCUSSION}

Five-fifteen percent of all adult spinal cord tumors are primary [4]. One third of all primary spinal cord

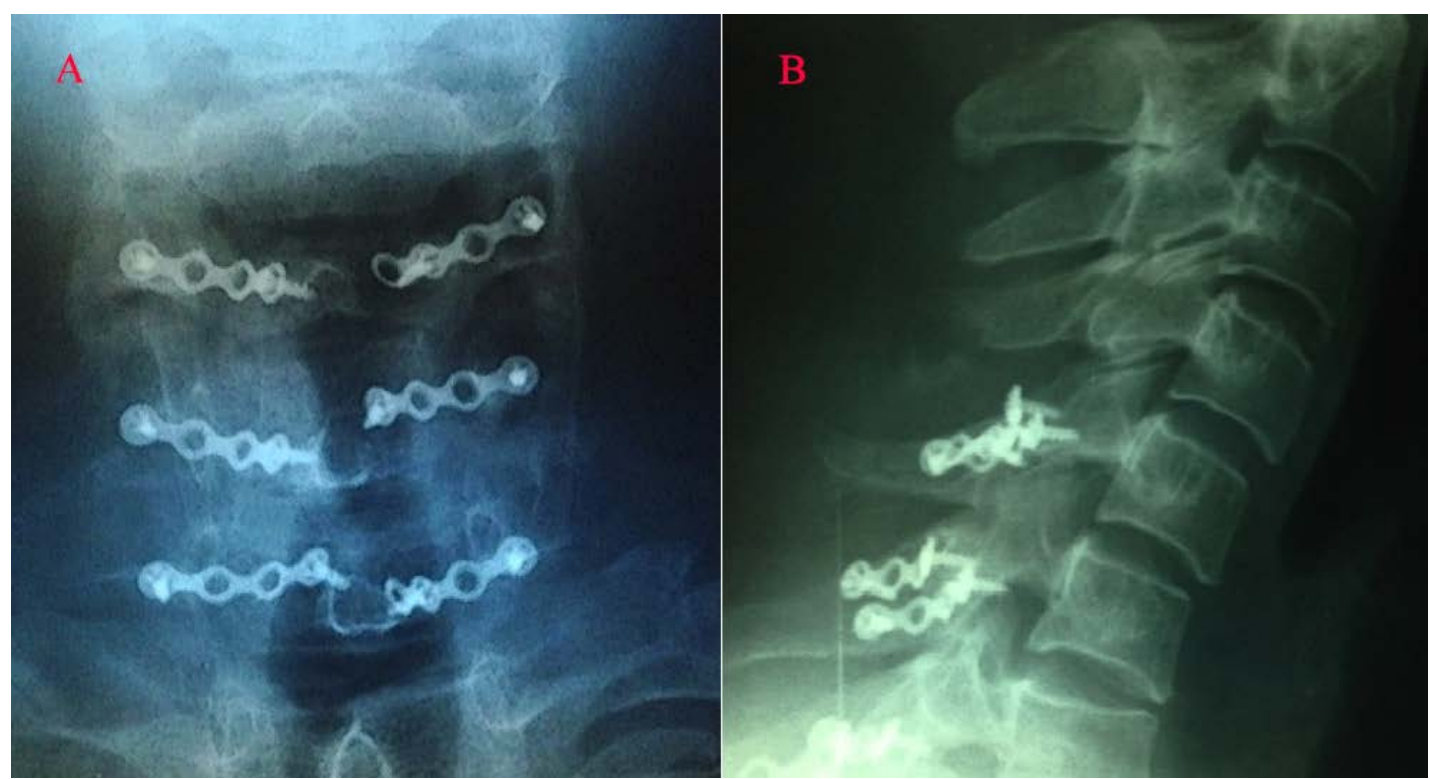

Figure 4. (A-B) Cervical x-ray taken postoperatively. 
tumors are schwannomas. Also, schwannomas are benign tumors whose most common location is intradural extramedullary [5]. Intradural extramedullary schwannomas may demonstrate a cystic, solid, or mixed character. On MRI study, these lesions are visualized as hypo-/isointense on T1 images, and hyperintense on $\mathrm{T} 2$ sequence $[5,6]$. Treatment options vary according to tumor localization, and the choice of surgery is determined by the surgeon's experience and dexterity. The preferred method may be tumor resection with laminectomy, with or without posterior stabilization. [7]. In the presented case, posterior stabilization was not preferred; instead, 3-level laminoplasty was performed, and there was no severe kyphosis on control X-ray at the end of the third postoperative month. The main advantages of minimal invasive surgery are reduced perioperative bleeding and shorter duration of postoperative hospital stay [8]. In our case, there was no need for erythrocyte replacement and the patient was discharged after two days. Another thing to consider for cervical schwannomas is that incidence of radicular dysfunction varies according to whether the tumor originates from the anterior or the posterior root. Tumor involvement in the anterior root is more likely to cause motor deficits [9]. In our case; there was no additional loss of motor and sensory function in the postoperative period.

\section{CONCLUSION}

In conclusion, giant cervical intradural extramedullary schwannoma with severe spinal cord compression is a rare entity. The presented case underwent total excision with laminoplasty, and developed no additional deficit. Also the cervical lordosis was mostly preserved without any need for stabilization. Laminoplasty is suitable in selected cases with relatively short segment involvement, especially if an appropriate cervical collar is used in the postoperative period.

\section{Informed consent}

Written informed consent was obtained from the patient for publication of this case report and any accompanying images.

\section{Conflict of interest}

The authors declared that there are no potential conflicts of interest with respect to the research, authorship, and/or publication of this article.

\section{REFERENCES}

[1] Iacopino DG, Giugno A, Gulì C, Basile L, Graziano F, Maugeri R. Surgical nuances on the treatment of giant dumbbell cervical spine schwannomas: description of a challenging case and review of the literature. Spinal Cord Ser Cases 2016;2:15042. [2] Mc.Cormick PC, Stein BM. Spinal Cord Tumors in Adults. In Youmans Julian R (Ed) Neurosurgical Surgery. 6th Edition. Volume 3, Ch 309. WB Saunders Company. 2011 (CD Edition). [3] Quillo-Olvera J, Lin GX, Kim JS. Severe spinal cord compression by pure giant intradural schwannoma of cervical spine. World Neurosurg 2018;110:17-9.

[4] Pan E, Prados MD. Spinal cord tumors, in Kufe DW, Pollock RE, Weichselbaum RR, et al (eds): Holland-Frei Cancer Medicine, 6th ed. Hamilton, ON: BC Decker, 2003.

[5] Conti P, Pansini G, Mouchaty H, Capuano C, Conti R. Spinal neurinomas: retrospective analysis and long-term outcome of 179 consecutively operated cases and review of the literature. Surg Neurol 2004;61:34-43; discussion 44.

[6] De Verdelhan O, Haegelen C, Carsin-Nicol B, Riffaud L, Amlashi SF, Brassier G, et al. MR imaging features of spinal schwannomas and meningiomas. J Neuroradiol 2005;32:42-9.

[7] Gu BS, Park JH, Roh SW, Jeon SR, Jang JW, Hyun SJ, et al. Surgical strategies for removal of intra- and extraforaminal dumbbell-shaped schwannomas in the subaxial cervical spine. Eur Spine J 2015;24:2114-8.

[8] Kim SH, Doh JW, Yoon SM, Yun IG. Huge schwannoma extended from craniocervical junction to upper thoracic spine. J Korean Neurosurg Soc 2003;34:589-92.

[9] Wong AP, Lall RR, Dahdaleh NS, Lawton CD, Smith ZA, Wong RH, et al. Comparison of open and minimally invasive surgery for intradural-extramedullary spine tumors. Neurosurg Focus 2015;39:E11. 